University of Nebraska - Lincoln

DigitalCommons@University of Nebraska - Lincoln

Faculty Publications, Department of Child, Youth, and Family Studies

Child, Youth, and Family Studies, Department of

2014

Examining Identity Consolidation Processes Among Ethnic

Minority Gay Men and Lesbians

Heather R. Kennedy

University of Nebraska-Lincoln, heather.kennedy@uni.edu

Rochelle L. Dalla

University of Nebraska-Lincoln, rdalla1@unl.edu

Follow this and additional works at: https://digitalcommons.unl.edu/famconfacpub

Part of the Developmental Psychology Commons, Family, Life Course, and Society Commons, Gender and Sexuality Commons, Other Psychology Commons, Other Sociology Commons, Politics and Social Change Commons, and the Race and Ethnicity Commons

Kennedy, Heather R. and Dalla, Rochelle L., "Examining Identity Consolidation Processes Among Ethnic Minority Gay Men and Lesbians" (2014). Faculty Publications, Department of Child, Youth, and Family Studies. 185.

https://digitalcommons.unl.edu/famconfacpub/185

This Article is brought to you for free and open access by the Child, Youth, and Family Studies, Department of at DigitalCommons@University of Nebraska - Lincoln. It has been accepted for inclusion in Faculty Publications, Department of Child, Youth, and Family Studies by an authorized administrator of DigitalCommons@University of Nebraska - Lincoln. 


\title{
Examining Identity Consolidation Processes Among Ethnic Minority Gay Men and Lesbians
}

\author{
Heather R. Kennedy and Rochelle L. Dalla \\ University of Nebraska-Lincoln, Lincoln, Nebraska, USA \\ Corresponding author - Heather R. Kennedy, Department of Child, Youth and Family Studies, \\ University of Nebraska-Lincoln, 135 Mabel Lee Hall, Lincoln, NE 68588-0236. \\ email hkennedy@huskers.unl.edu
}

\begin{abstract}
Past scholarship has demonstrated shortcomings in developmental theories for both sexual and ethnic identity. Furthermore, identity development may be especially challenging for members of multiple minority groups facing significant social stressors. The primary goal of this study was to explore identity consolidation processes among individuals with intersecting minority identities. Using in-depth, personal interviews and self-report measures, data were collected from 16 ethnic minority gay men and lesbians. Themes such as acceptance, invisibility, and fear confirm the influence of social context on identity integration. Findings revealed differing magnitudes of consolidation. Greater social support and educational endeavors were critical factors in distinguishing participants' extent of integration. Implications for practice and research are presented.
\end{abstract}

Keywords: identity development, ethnic identity, sexual identity, gay/lesbian and qualitative 


\section{Introduction}

Achieving a positive and coherent identity is a primary task of adolescence and prepares individuals to form healthy intimate relationships (Erikson, 1968; Graber \& Archibald, 2001; Phinney \& Rosenthal, 1992). However, identity development is no longer considered solely as a stage of development but is viewed, rather, as a lifelong process which involves forming an autonomous self (Coté \& Levine, 2002), establishing an internally consistent set of goals, self-perceptions, and behaviors (Dunkel, 2005), making and identifying with a set of life commitments (Luyckx, Goossens, Soenens, \& Beyers, 2006), and perceiving oneself as an adult and as supported by a validating adult community (Luyckx, Schwartz, Goossens, \& Pollock, 2008). By extension, identity consolidation is defined as "a multidimensional construct that subsumes several components of identity work [including]: making and identifying with commitments, integrating various aspects of one's identity into a coherent whole, developing consistency across time, and perceiving oneself as an adult and as a member of an adult community" (Schwartz et al., 2010, p. 215). For those individuals who belong to distinct social groups, such as ethnic and sexual minorities, establishing a consolidated sense of self requires they search, explore, commit, and unify, rather than compartmentalize, multiple social and personal identities (Rotheram-Borus \& Langabeer, 2001; Tragakis \& Smith, 2010).

\section{Ethnic Minority Identity Development}

Initial research on identity development focused on the White population, but in 1971 William E. Cross Jr. proposed one of the original and most researched models of racial identity development (Constantine, Richardson, Benjamin, \& Wilson, 1998; Cross, 1995; Vandiver, 2001). The Cross (1971) model presented a five-stage process (i.e., pre-encounter, encounter, immersion/emersion, internalization, and internalization/commitment) that proposed achieving a healthy racial identity required progress through stages from psychologically damaging (e.g., beliefs of racial inferiority) to psychologically beneficial (e.g., self-acceptance, culturally affirming, racial transcendence). Phinney has been credited with significantly contributing to the discourse of ethnic identity by adapting and extending research from the early 
developmental models. Rather than focus on a single ethnic group, she developed and tested a model applicable to various ethnic groups and focused on the processes rather than the content of developing an ethnic identity (Ong, Fuller-Rowell, \& Phinney, 2010). In her model, the process of ethnic identity development is characterized by periods of indifference, exploration and change, and integration (Ong et al., 2010; Phinney, 1989, 1993). However, the process is not assumed to be strictly linear.

Early research concluded there were significant relationships between initial developmental stages and lower levels of psychological well-being (Martinez \& Dukes, 1997; Phinney, 1989, 1992; Phinney \& Alipuria, 199o; Phinney, Cantu, \& Kurtz, 1997; Pyant \& Yanico, 1991) and negative associations between ethnic identity and depression (Roberts et al., 1999), and longitudinal research supported the developmental progression of ethnic identity (Phinney \& Chavira, 1992). More recently, research findings validated the process of ethnic identity development proposed by Phinney across a large group of ethnically diverse individuals (Syed \& Azmitia, 2008). A meta-analysis concluded that ethnic identity was consistently and positively correlated with self-esteem and well-being (Smith \& Silva, 2011). Strong ethnic identification was significantly associated with positive social functioning and less substance use (Galliher, Jones, \& Dahl, 2011). Furthermore, ethnic identity was significantly and negatively correlated with symptoms of depression (Miranda, Polanco-Roman, Tsypes, \& Valderrama, 2013) and depressive symptoms related to ethnic discrimination are buffered by ethnic identity (Mossakowski, 2003).

\section{Sexual Minority Identity Development}

Cass (1979) developed the most widely researched model of sexual minority identity development (Ellis \& Mitchell, 2000) and it proved foundational to many later models offered by various scholars (Morgan, 2012). The Cass model was influenced by the work of Cross and is based on the assumption that integration of a sexual minority identity is a developmental process and influenced by interaction between the individual and his or her environment. This psychosocial model presented a six-stage process (i.e., confusion, comparison, tolerance, acceptance, pride, and synthesis) that proposed achieving a healthy gay or lesbian sexual identity required progression from awareness 
of same-sex thoughts, feelings, and/or behaviors to acceptance and recognition of a non-heterosexual identity (publicly and privately) to integration with other aspects of self (Cass, 1979). Early research provided empirical validation for the sexual identity developmental models, with strongest evidence for the early and late stages (Cass, 1984; Fassinger \& Miller, 1996; Degges-White, Rice, \& Meyers, 2000; Kahn, 1991; Sophie, 1986), and indicated that significantly greater psychological well-being was demonstrated by individuals in later stages of development (Brady \& Busse, 1994; Levine, 1997). Although none of these studies appear to have controlled for age, they consistently showed later stages corresponded to better well-being. More recently, empirical corroboration for the Cass model was noted in that the stages were predictive of affective outcomes (e.g., shame, personal mastery) and discriminated across variables (Greene \& Britton, 2013). Furthermore, a recent qualitative investigation by Adams and Phillips (2009) found that two of six Native American non-heterosexuals followed the Cass developmental course.

However, scholars argued that there exists variation in non-heterosexual identity development (Savin-Williams \& Diamond, 2000; Savin-Williams, 2005). For males, this variation concerned sexual behavior and identification as non-heterosexual (Dubé, 2000) and for females it appeared as fluidity in sexual behavior and labeling of sexual identity (Diamond, 1998, 2000). Some research has provided support for these alternative models of sexual identity development (DeggesWhite \& Myers, 2005; Diamond, 2005).

Yet, there remains a lack of clarity regarding sexual identity development given that research has documented both consistency and variability (Diamond, 2000, 2003; Rosario, Schrimshaw, Hunter, \& Braun, 2006), especially as it extends beyond identity formation (e.g., self-labeling and same-sex sexual behavior) to identity integration. It has been found that identity integration is initiated by selflabeling and/or same-sex behavior, but this alone is not adequate to maintain the process of integration (Rosario, Schrimshaw, \& Hunter, 2008). Importantly, individuals with a more achieved sexual minority identity demonstrated better mental health (Feldman \& Wright, 2013). This issue remains of critical importance given that research has provided evidence, although not uncontested, that sexual minorities are at risk for compromised emotional well-being (Herek \& Garnets, 2007; Cochran \& Mays, 2009), resulting from multiple factors 
including experiences with minority stress (Meyer, 2003) and victimization (Russell, Ryan, Toomey, Diaz, \& Sanchez, 2011).

\section{Ethnic and Sexual Minority Identity Development}

Early scholarship on identity development of individuals with multiple minority statuses included largely theoretical writings that proposed ethnic minority non-heterosexuals may encounter more barriers in developing a healthy identity such as facing multiple layers of oppression (Harper, Jernewall, \& Zea, 2004) and perceiving these identities as incongruent and forced to choose between the two (Greene, 1997; Savin-Williams \& Rodriguez, 1993). Early empirical research demonstrated support with findings that included the following:

- experiences of racism in the lesbian, gay, bisexual, and transgender (LGBT) community (Adams \& Kimmel, 1997),

- non-acceptance in ethnic communities (Loiacano, 1993),

- cultural denial of same-sex-attracted individuals (Chan, 1993),

- invisibility within the family of sexual minority member (Espin, 1993),

- pressure to choose between ethnic and sexual identity (Dubé \& Savin-Williams, 1999),

- internalized conflict from dual identities (Colon, 2001), and

- higher levels of psychosocial distress among participants that felt negatively about these dual minority identities (Crawford, Allison, Samboni, \& Soto, 2002).

However, scholars argued that early studies provided inconsistent results regarding the proposed delay or deficits in sexual identity development for ethnic minorities (Rosario, Schrimshaw, \& Hunter, 2004). In comparing groups of ethnic minority and White individuals, scholars found no differences in sexual identity formation such as same-sex behaviors and self-identification (Dubé \& Savin-Williams, 1999; Rosario et al., 2004), but differences in identity integration were found in which Black and Latino participants disclosed their sexual orientation to fewer individuals than White participants (Rosario et al., 2004). Similarly, African-American and Latina lesbians required more time to self-identify and were less likely to disclose to others outside their family than White lesbians, although they were typically 
younger when they recognized their same-sex interest and disclosed their non-heterosexual identity more quickly (Parks, Hughes, \& Matthews, 2004). As a composite group, African-American and Latino sexual minorities did not differ from their White peers on measures of social or psychological well-being (including depression), but Latino participants demonstrated significantly more depressive symptoms and lower levels of psychological well-being than White participants (Kertzner, Meyer, Frost, \& Stirratt, 2009). Recent research found that Asian and Pacific Islander men with more positive attitudes toward their ethnic identity held more positive attitudes toward their sexual minority identity (Vu, Choi, \& Do, 2011), and those experiencing more ethnic identity stress displayed greater sexual identity stress (Chen \& Tryon, 2012).

It has been argued that there is insufficient knowledge regarding the influence of social contexts in ethnic minority identity development (Umaña-Taylor, 2004) and that sexual identity development models failed to acknowledge the multiple sociocultural contexts that affect development in ethnic minority gay men and lesbians (Parks et al., 2004). However, several decades ago a theoretical model proposed that the main mechanisms in individual development were the progressively more complex interactions that occur between a person and the environment and these vary based on the characteristics of the person, his or her social contexts, and time (Bronfenbrenner \& Morris, 2006; Foster \& Kalil, 2005). Many scholars have identified the importance of examining the role of context in the process of identity development (Chun \& Singh, 2010; Frable, 1997; Grotevant, 1987; Phinney, 2008) and research found that context (i.e., micro and macro) influenced the salience of ethnic identity and ethnic identity achievement (Umaña-Taylor \& Fine, 2004). Yet, it was not until 2008 that scholars examined contextual factors that impeded or facilitated identity integration for sexual minorities (Rosario et al., 2008). Ethnic minority gay men and lesbians with stronger ethnic identities and greater openness about their sexual orientation with family and community reported more satisfaction with social support (Gallor \& Fassinger, 2010). However, other narrative accounts identified the church and family contexts as sources of stress, and for some individuals, eventual sources of support (Narváez, Meyer, Kertzner, Ouellette, \& Gordon, 2009). 
These diverse findings reflect the novelty of research examining the intersection of multiple minority identities (Morgan, 2012) and there remains a shortage of empirical literature focused on ethnic minority non-heterosexuals (DeBlaere, Brewster, Sarkees, \& Moradi, 2010). Although the body of scholarship is growing, a review of empirical studies from 1998-2007 revealed significant limitations that included the following:

- disproportionately more male participants,

- more than $80 \%$ of the studies focused on a single gender,

- almost half involved only a single ethnic minority group,

- more than 80\% sampled from only four states (i.e., California, New York, Illinois, and Florida),

- more than half gathered participants from bars/clubs and clinical settings and focused on pathology/symptomology, and

- fewer than 20 studies used a mixed-method design (Huang et al., 2010).

Thus, the current study addressed several of these limitations by purposefully acquiring a diverse sample. This sample includes men and women from various ethnic minority groups, ranging in age, that were recruited from an inadequately represented locale (i.e., the Midwest) and a variety of places excluding bars and clinical settings. In addition, by incorporating both quantitative and qualitative approaches, this study enhances the body of literature that mainly consists of studies using the traditional quantitative methodology for investigating intersectionality (Parent, DeBlaere, \& Moradi, 2013).

With a mixed-methods design, this study used complementary theoretical frameworks to offer unique perspectives and increased understanding of a complicated topic. The developmental models of ethnic and sexual minority identity by Phinney and Cass guided the creation of interview questions focused on identity synthesis (e.g., "How do you feel about these two identities?”) and enhanced objectivity in analysis of identity integration. However, the authors felt the developmental models inadequately addressed the influence of social context in the process of identity consolidation. Thus, the bioecological model (Bronfenbrenner, 1979) was incorporated and enabled us to explore and analyze factors that facilitate and hinder integration based on the 
proposition that individual development occurs through complex, distinct, and reciprocal interactions in a nested set of ecosystems (Bronfenbrenner \& Morris, 2006). This study explored several critical microsystems including the family, peers, coworkers, and ethnic and gay communities. Also examined were developmental interactions in the mesosystem (e.g., family and religious organization), the exosystem (e.g., family relations with others in their ethnic community), the macrosystem (e.g., cultural attitudes, policies/laws), and the chronosystem (e.g., across time). In concert with the selected theoretical frameworks, the quantitative measures gathered individuals' perspectives from an empirical distance, while the in-depth interviews obtained a more comprehensive representation (Denzin \& Lincoln, 2011).

It is clear that there remains a need for additional research that focuses on the developmental processes for those with intersecting ethnic and sexual minority identities. The purpose of this study was to understand the identity consolidation processes for ethnic minority gay men and lesbians. To this end, the research was designed to (1) assess the extent to which participants had consolidated their ethnic and sexual identities; (2) examine identity consolidation processes across key social contexts; and (3) identify factors which promote consolidation. This study extends the limited research on processes rather than milestones of sexual identity formation (Jamil, Harper, \& Fernandez, 2009), explores dimensions beyond those most frequently used such as internalized homophobia (Mohr \& Kendra, 2011), and supplements the limited research concerning the influences of social context on identity consolidation (Bregman, Malik, Page, Makynen, \& Lindahl, 2013; Rosario et al., 2008). This article contends that interactions within key social contexts influence the process of identity integration. Individuals that assert their ethnic and sexual identities as salient and valued in their overall sense of self, across multiple domains, exhibit a fundamental marker of a consolidated identity.

\section{Method}

A pragmatic methodological worldview guided this study. The pragmatic approach views reality as both singular and multiple, believes knowledge can be both objective and subjective, realizes researchers can hold both biased and unbiased views, and advises that the research 
questions dictate the selection of methodology and rhetoric because there is validity in all approaches (Creswell \& Plano Clark, 2011). Pragmatism appeared an ideal approach because it suits a mixed-method design (Johnson \& Onwuegbuzie, 2004), operates from the stance that gathering multiple perspectives can often best inform the problem (Greene \& Hall, 2010), and is beneficial when information from only one data source would be insufficient (Creswell \& Plano Clark, 2011). It is also important to note that the current study was motivated by the first author's awareness of societal privileges impacted by her female gender, although not a member of an ethnic minority, and as a counseling professional it was important to understand developmental influences for individuals with multiple devalued social identities. The authors believe their position enhanced the research process because they were attuned to the premise that advantages and disadvantages accompany privileged social identities.

\section{Participants}

A total of 16 individuals ( 11 male and 5 female) participated in the study. Participants ranged in age from 21 years to 64 years $(M=33$ years). Self-identified sexual orientation of participants was as follows: gay $(N=10)$, lesbian $(N=5)$, and same-sex thoughts, feelings, desires, or behaviors $(N=1)$. Participants represented a diverse range of ethnicities, including Hispanic/Latino/a $(N=9)$, African-American/Black $(N=2)$, Asian/Asian-American $(N=1)$, Middle Easterner/ Arab-American $(N=1)$, African-American and White $(N=1)$, White and Hispanic $(N=1)$ and Black Latino $(N=1)$. In terms of formal education, most of the participants $(N=6)$ had earned a high school diploma followed by a bachelor's degree $(N=4)$, a master's degree ( $N$ $=3$, some college or vocational training $(N=2)$, and a doctoral degree $(N=1)$. Participants' total annual income was as follows: less than \$10,00o ( $N=2)$, \$10,0oo-19,999 ( $N=1)$, \$20,ooo-29,999 ( $N$ $=6)$, \$30,000-\$39,999 $(N=3), \$ 40,000-49,000(N=3)$, and more than $\$ 50,000(N=1)$. With regard to religious affiliations, most $(N=$ 7) were Catholic, with the remainder identifying themselves as nonpracticing Christian $(N=2)$, Methodist $(N=2)$, Christian $(N=1)$, or spiritual $(N=1)$. Three reported no religious affiliation. In addition, all names are pseudonyms. 


\section{Measures}

\section{Demographic Information}

Participants completed a questionnaire that inquired about sex, age, ethnicity, education, income, and religious affiliation.

\section{The Stage Allocation Measure}

The Stage Allocation Measure (SAM) by Cass (1984) assessed non-heterosexual identity by asking participants to select one of seven narrative profiles that best described them at the present time. The seven sexual identity profiles include

1. Pre-Stage 1,

2. Stage 1-Identity Confusion,

3. Stage 2-Identity Comparison,

4. Stage 3-Identity Tolerance,

5. Stage 4-Identity Acceptance,

6. Stage 5-Identity Pride, and

7. Stage 6-Identity Synthesis.

This measure has shown content, concurrent, and construct validity (Kahn, 1991).

\section{The Gay Identity Questionnaire}

In addition to self-assignment by the SAM, the Gay Identity Questionnaire (GIQ) (Brady \& Busse, 1994) was used to assess acquisition of a coherent non-heterosexual identity. It is based on the Cass model and composed of 45 randomly ordered true and false statements. The subscale with the highest total score was the participant's designated stage and a dual-stage designation was given if two or more subscales accrued equal total scores. The stage identity profiles include the following:

1. Stage 1-Identity Confusion,

2. Stage 2-Identity Comparison, 
3. Stage 3-Identity Tolerance,

4. Stage 4-Identity Acceptance,

5. Stage 5-Identity Pride, and

6. Stage 6-Identity Synthesis.

Using the Kuder-Richardson formula, adequate internal consistency was found in the current study for Stage $4(r=.79)$ and Stage $6(r=$ .70 ), which is similar to the results of Brady and Busse (1994) of $r=$ .71 and $r=.78$, respectively. Lower internal consistency was noted in the present study for Stage $3(r=.59)$ and Stage $5(r=.15)$ compared to earlier findings of $r=.76$ and $r=.44$, respectively (Brady \& Busse, 1994). In the present study, no participants received Stage 1 or 2 designations, which is consistent with earlier research that could not assess the reliability of those stages due to too few participants (Brady \& Busse, 1994).

\section{The Multigroup Ethnic Identity Measure}

The Multigroup Ethnic Identity Measure (MEIM) by Phinney (1992) was used to assess development of ethnic identity. The measure consists of 14 positively and negatively worded items that assess three aspects of ethnic identity: Affirmation and Belonging, Ethnic Behaviors, and Ethnic Identity Achievement (Phinney, 1992). In addition, there are six positively and negatively worded items that assess Other-Group Orientation (Phinney, 1992). The responses were rated on a 4-point scale (1 = strongly disagree, 4 = strongly agree). Each participant received a mean score for each subscale and the total scale, with higher scores reflective of a stronger sense of belonging and a more achieved ethnic identity (Phinney, 1992).

The present study demonstrated good internal consistency for the ethnic identity scale $(\alpha=.85)$, which is consistent with prior research ( $\alpha=.81-.90)$ by Phinney (1992). In this study, most subscales demonstrated adequate internal consistency: affirmation and belonging ( $\alpha$ $=.75)$, ethnic identity achievement $(\alpha=.64)$, ethnic behaviors $(\alpha=$ $.73)$, and other-group orientation $(\alpha=.58)$. These results are similar to Phinney's (1992) findings which were as follows: affirmation and belonging ( $\left.\alpha=.75^{-.86}\right)$, ethnic identity achievement $(\alpha=.69-.80)$, and other-group orientation $(a=.71-.74)$. 


\section{Procedures}

Participants were recruited from two medium-sized cities in a Midwestern state using purposeful criterion-based sampling strategies (Creswell, 2007; Merriam, 2009) which included maximum variation, based on gender and ethnicity, and snowball techniques in order to document patterns and variations (Creswell \& Plano Clark, 2011; Teddlie \& Yu, 2007). Study inclusion criteria required participants be 19 years of age or older, a member of an ethnic or racial minority group, and self-identified as gay, lesbian, or someone with same-sex thoughts, feelings, desires, or behaviors (SSTFDB). At initial contact the author(s) confirmed with potential participants they felt secure in their ability to communicate proficiently in English. The first author provided written recruitment materials to key informants (e.g., professionals working with ethnic and sexual minorities) to distribute to eligible potential participants. If interested in volunteering, eligible participants then contacted the first author to arrange an interview. At the completion of the interview, the author(s) provided study participants with written recruitment materials and instructions to forward to potential participants.

This research received institutional review board approval and was in accordance with the ethical standards of the American Psychological Association. After initial contact, an interview meeting time and location (e.g., private and convenient) was selected. Upon arriving at the site, standard procedures were followed, which included obtaining informed consent from each participant. Participants completed a set of self-report measures, followed by an individual interview by either the first or second author using a semistructured format with a predefined set of open-ended questions. Participants were encouraged to talk freely to capture and clarify the processes under study. For example:

- Please describe yourself as both [ethnic identity] and [sexual identity].

- How do you feel about these two identities? How has this changed?

- How have you managed these dual identities within your family? 
- Please describe your involvement in your [ethnic, gay] community. What has facilitated or prevented this involvement?

The interviews were audiotape recorded and lasted 90 to 120 minutes. Participants did not receive monetary compensation.

\section{Data Analysis}

For the quantitative measures, preliminary analyses were conducted to assess psychometric properties of the measures and gather descriptive statistics. Interviews were transcribed verbatim by the first author and then analyzed by the authors using thematic analysis, a process of encoding qualitative information by identifying themes and patterns of behavior (Aronson, 1994; Boyatzis, 1998). After an initial thorough read of each transcript, the raw information was reduced by coding the data into segments relevant to the purposes of the investigation (Creswell, 2007; Merriam, 2009). The segments of data for each individual participant were combined into broader categories and themes, and then compiled into a table that allowed for both within- and across-participant data analyses. This reflected the analysis process of description, classification, and interpretation (Creswell, 2007). During this process, the transcripts were read multiple times to ensure all relevant information was captured regarding identity consolidation.

Finally, several validation strategies were used including triangulation, member checking, rich descriptions (Creswell, 2007), and saturation (Merriam, 2009). Multiple methods of measurement, both qualitative and quantitative, were used in the study. Two participants reviewed the results and in feedback to the first author verified that they felt the quoted material and interpretations reflected their statements and the context of their interviews. The authors provided detailed descriptions and engaged in data collection until saturation was reached. 


\section{Results}

\section{Goal One: Assess the Extent to Which Participants Had Consoli- dated Their Ethnic and Sexual Identities}

First, it is important to note that the results of the self-report measures indicated the sample was fairly advanced in development of their sexual identity given that the majority of participants $(N=11)$ selected the narrative profile of Identity Synthesis on the SAM and most $(N=10)$ were designated into Identity Synthesis on the GIQ. However, analysis of the qualitative data revealed clear distinctions between participants in the degree to which they had integrated their ethnic and sexual identities. This resulted in two groupings of participants and was supported by nuances in the results from self-report instruments, including greater variation among participants in terms of ethnic identity on the MEIM (refer to Table 1 for descriptive statistics).

Table 2 provides a profile of participants and includes quantitative and qualitative data displaying the differences between the groups based on the magnitude of integration of sexual and ethnic identities.

\section{Interwoven}

Of the total sample, eight participants (i.e., six gay men and two lesbians) appeared to demonstrate, through both qualitative and quantitative data, the integration of both their ethnic and sexual identities into their overall personal identity. The average age of this group was 36 years, the majority had earned a bachelor's degree or higher, and the mode annual income was \$30,000-39,000. These participants demonstrated consistently high scores across the self-report instruments,

Table 1. Multigroup Ethnic Identity Measure (MEIM) Descriptive Statistics

$\begin{array}{lllllll}\text { Scale } & M & S D & \text { Minimum } & \text { Maximum } & \text { Range } & N \\ \text { Total Score } & 3.19 & .54 & 2.29 & 4.00 & 1.71 & 16 \\ \text { Affirmation \& } & 3.36 & .65 & 2.20 & 4.00 & 1.80 & 16 \\ \quad \text { Belonging } & & & & & & \\ \text { Achievement } & 3.18 & .50 & 2.43 & 4.00 & 1.57 & 16 \\ \text { Behaviors } & 2.78 & .89 & 1.00 & 4.00 & 3.00 & 16 \\ \text { Other-Group } & 3.67 & .43 & 2.50 & 4.00 & 1.50 & 16 \\ \quad \text { Orientation } & & & & & & \end{array}$




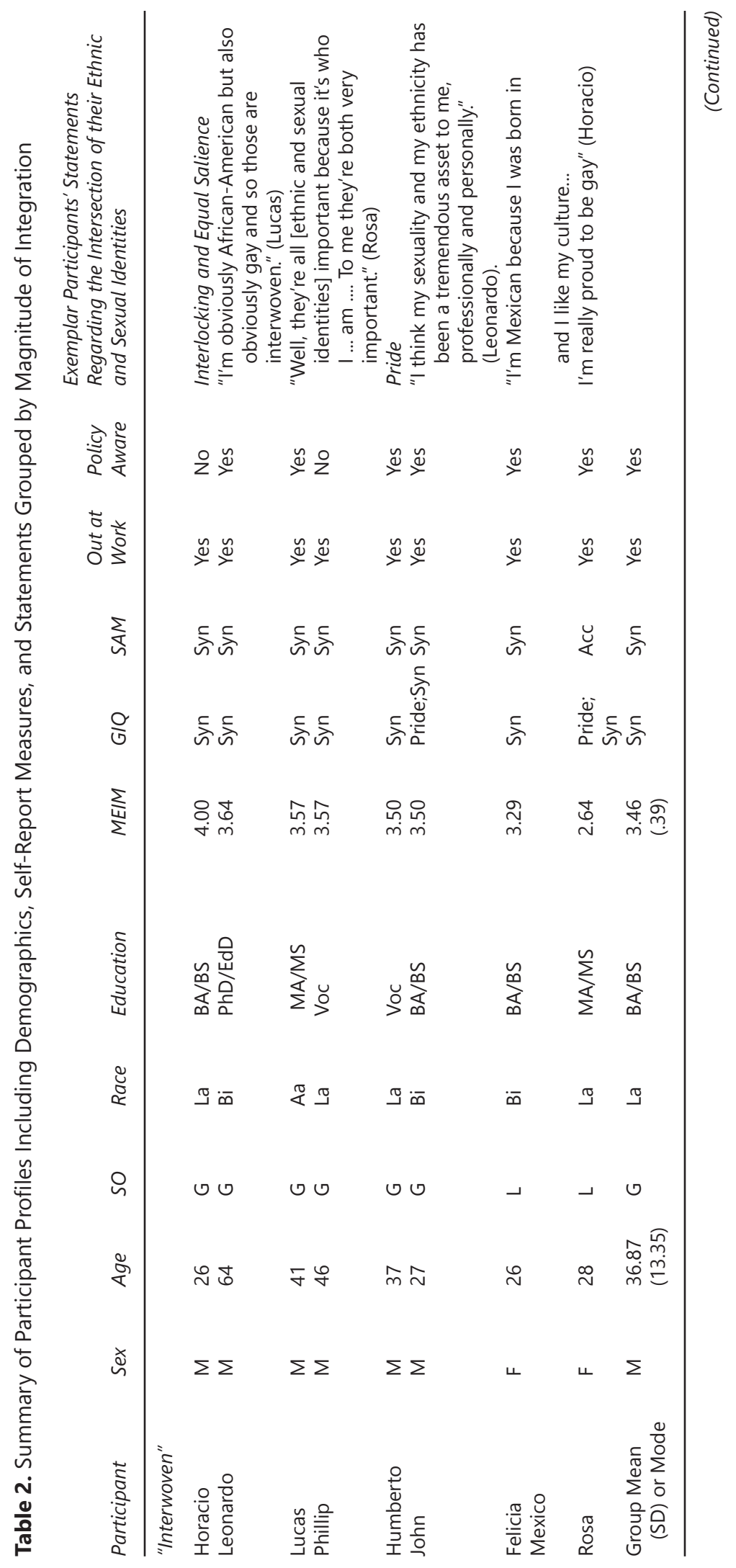




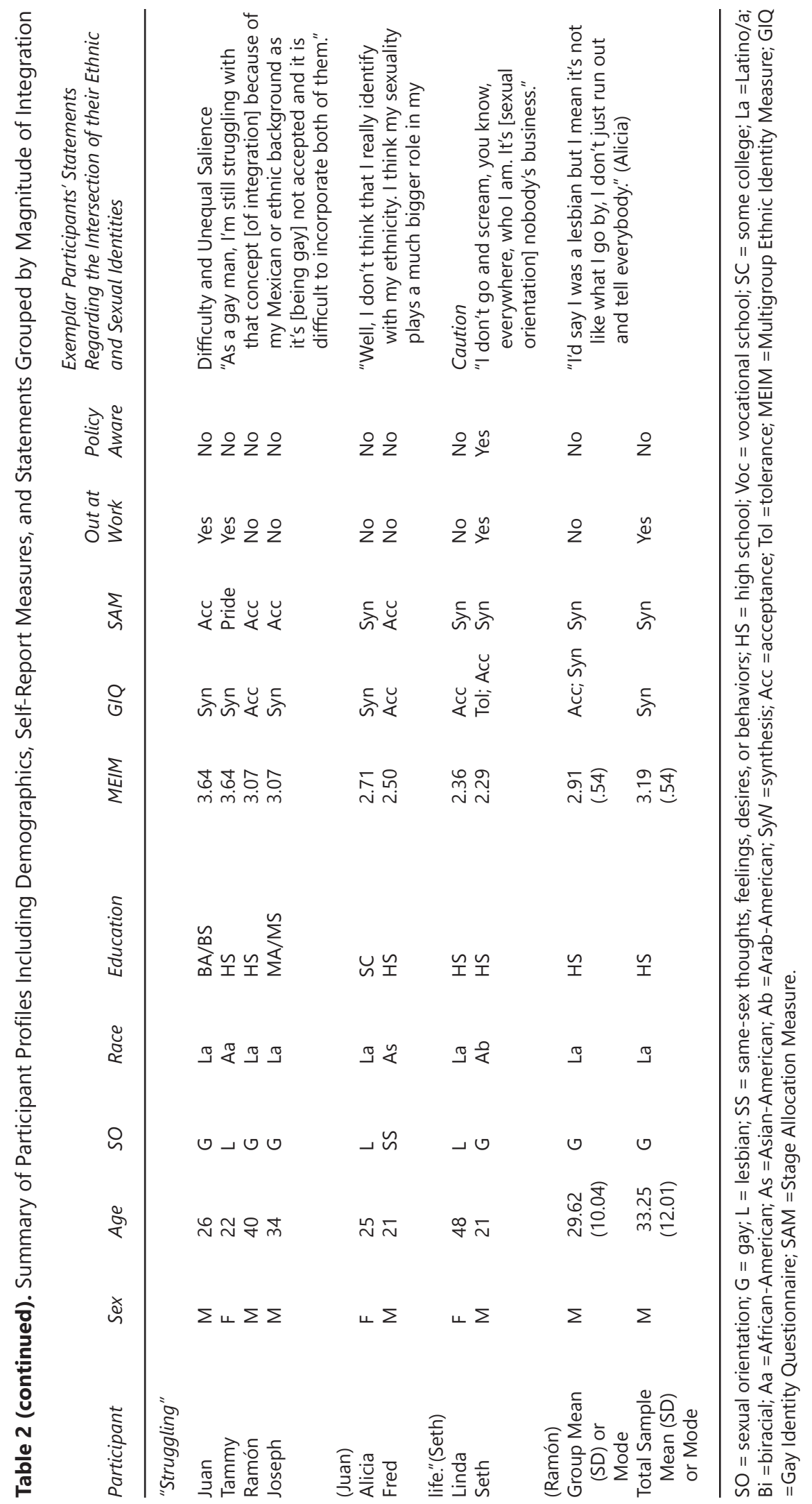


with almost all receiving a MEIM total score above the sample mean and being designated into the highest profile (i.e., Identity Synthesis) of sexual identity. All of these participants verbalized having disclosed their sexual identity to friends, family, and coworkers. The majority described an awareness of laws/policies impacting them based on their minority statuses and engaged in political activism.

Throughout the qualitative interviews, these participants verbalized awareness of these two minority identities, their process in integrating the two identities into their overall personal identity, and outcomes resulting from identity consolidation. They detailed the intersection of these two identities, including the difficulty separating them, and the equal salience they held within their lived experience. For example, Leonardo stated, “... it's very difficult to separate them [ethnic and sexual identity]" and Humberto commented, "I can honestly say that both [ethnic and sexual identity] are equally as important." These participants also expressed pride in their ethnic and sexual identities, as summarized by Phillip: "Everybody that I associate with knows and they know that I raised my kids in an openly gay home. I've never denied who I was because I'm happy with who I am.”

"Struggling"

In contrast, the remaining eight participants appeared to demonstrate a lesser degree of consolidation of their ethnic and sexual identities across self-report measures and in-depth interviews. The average age of this group was 29 years, the majority had earned a high school diploma, and the mode annual income was $\$ 20,000-29,000$. For these participants, there was greater individual inconsistency in the data, with many demonstrating lower scores across the self-report measures. Almost all of these participants scored below the sample mean on the MEIM and were designated into a middle stage (e.g., Acceptance) of sexual identity development. The majority of these participants had disclosed their sexual identity to most friends and some immediate family members (i.e., parents or siblings but not both). In contrast to their "interwoven" peers, most of them had not disclosed their sexual identity to coworkers, could not identify any laws/policies impacting them because of these minority statuses, and denied any forms of activism. 
Throughout the qualitative interviews, these participants expressed challenges in the process of integrating their ethnic and sexual identities. Fred noted, “I don't know. Trying to blend in with everybody else pretty much and being gay, I guess, kind of puts a damper sometimes...." They expressed an unbalanced salience of these identities in their lives, as noted by Alicia's comment: "I suppose my sexuality would be more important... ." Finally, they described the caution they exhibited in interactions with others, as exemplified by Juan's statement:

I think the way that I separate how I label myself is whether or not any of my family members are around, my immediate family as well as my cousins. If any of them are around then I'm not openly as gay as I am if I'm away from my whole family.

\section{Goal Two: Examine Identity Consolidation Processes Across Key Social Contexts}

In exploring the integration of these dual minority identities in key social contexts, regardless of level of integration, these participants clearly depicted factors influencing their consolidation within the family, culture, occupational, and religious domains.

\section{Family and Culture}

For these participants, it appeared that the intersection of their ethnic and sexual identities was most apparent within the family contextextending into their larger ethnic culture. Despite a strong identification with their family's ethnic heritage, participants were confronted with the convergence of these two identities as they gained an awareness of their same-sex attractions. As noted by Lucas, "I grew up in a predominately African-American community ... as an African-American I didn't feel like an outsider but once I realized, at a very early age, that I was gay, I felt like an outsider."

Addressing "fear". Once they began recognizing their non-heterosexual identity, 14 of the 16 participants faced fears of rejection from their families which prevented or delayed disclosure and, by extension, incorporation of their ethnic and sexual identities within the 
family context. For example, Linda remembered specific incidents such as "... sitting at family dinners on Sundays and hearing your grandpa talk about 'fucking queers,' [not] being accepted by my family.” Similar experiences were described by Tammy: "At first I was really scared to come out and so that was the last thing I wanted to do was lose my parents because I came out...." Furthermore, most of the participants described this fear of family rejection stemming from their larger ethnic culture. Humberto summarized this experience:

My culture and actually my dad, my dad was Mexican, he was "the culture" and he died when I was seventeen. Up until I was seventeen I had done everything I was supposed to do, that a typical seventeenyear-old male was supposed to do. I dated women, I slept with a lot of women, I played sports... these were just things that were expected of me. When he passed away it was as though the shackles finally came off and I had to learn how to be who I really am and that is [a] gay [man] who happens to be Hispanic also.

"Invisibility". In relation to dealing with fear of family rejection in the quest to integrate these two aspects of self, several participants described having to navigate these intersecting identities from within a culture where a minority sexual identity was obscure. Rosa explained:

Definitely the culture-that invisibility, that lack of awareness of it. It doesn't mean it doesn't exist; it's just, here you have PFLAG [and] that doesn't exist there [her native country].... I never had a sense that it was okay or there was some sort of support ... never heard even the word.

Confronting "cultural norms and cultural expectations". Within the family, and extending into their larger cultural communities, 14 of the 16 participants described that in attempting to integrate their ethnic and sexual identities they had to confront their culture's expectations based on gender and heterosexism, in addition to the perceptions and assumptions about gay men and lesbians. For many, this hindered (or still impedes) their involvement in the larger ethnic community. Rosa noted, "I definitely would say my culture. My culture is very gender oriented, everything is feminine, masculine.... You have to fit in those [roles]." More specifically, John noted the following:

What prevented [my coming out] was the culture, the cultural norms, the cultural expectations that were set.... So trying to come out and trying to face that is very tough because of the traditional 
role is that you get married, you have children, you are a good Catholic family. And so that prevented me from coming out because I didn't want to be a disappointment.

In addition, others described more specifically the influence of the cultural typecasting and the negative assumptions and stereotypes of gay men and lesbians. For example, Leonardo commented, "I did perhaps have a sense that people thought that gay people were weak... ." Horacio summarized it this way:

It's [Mexican culture] really different. I mean, the culture it's, like, you know, machismo. It's really difficult for men to accept gay people ... the images in Mexico to be gay is really different than here. To be gay in Mexico is more like a man who dresses like a woman ... so they don't understand to be gay is just your sexual identity....

"Fought with religion". In addition to family and ethnic communities, the meeting of these two facets of self was clearly evident in the religious/spiritual context of participants' lives. All sixteen individuals reported a religious upbringing in Christianity, with the majority being reared in the Catholic faith $(N=10)$, and one being exposed to the Muslim religion. Most described their childhood steeped in religion as exemplified by Lucas's statement, "I grew up in Virginia, Southern Baptist ... my family was always at church...." Several explained the deep connection between their faith and their ethnic identity. Juan said, "Being Mexican has enriched my religious life because family and religion and being Mexican-it's all one. I mean, you're not one without the other...."

However, once aware of their same-sex attractions all participants, in varying magnitudes, described feeling condemned, alienated, and/ or rejected by their religious communities. Linda stated, "I fought with religion for a long time because of the God thing ... it was a struggle ... ." Fred commented, "Being Southern Baptist, it's [non-heterosexuality] strictly, very strictly prohibited. So, I thought 'I'm never going to go to the good place, I guess heaven or whatever."' Finally, John said, "It's hard because that church that you've always grown to love and adore and you grew up with is so anti the other side of you, it's so anti-gay .... It's very hard and it hurts a lot."

"Losing my job". Although slightly less prominent, attempts to merge both ethnic and sexual identities in the workplace presented some interesting results. Eight participants felt advantaged in the 
workplace due largely to knowledge and specific skills (e.g., bilingual) associated with their ethnicity. This is illustrated in Juan's response:

Being Mexican has helped me for the most part because of my bilingual skills. It's always been an asset to be bilingual and has allowed me to get hired quickly, get paid more than somebody else for doing the same type of job.

However, the majority of participants clearly described that in order to incorporate their sexual identity into their occupational lives they had to confront the harsh realities of being a sexual minority in the workplace. Often due to the lack of legal protection, these cruel realities included fear of gossip from coworkers, losing coworkers as resources and mentors, a hostile work environment (e.g., jokes), being subjected to discrimination, and even losing their jobs. As Rosa explained, “The fact that there's no protection legally makes their opinions and their judgment more powerful ....” Finally, John summarized occupational challenges and fears as follows:

The fear of losing my job because I was starting to be a teacher and my district ... they shot down adding sexual orientation to the nondiscriminatory clause. So I knew there was big risks and all the stereotypes that go along with being an out teacher or being an out gay man .... Every day I take risks. I'm out to my building, the entire staff knows .... So all it would take is one parent to call our superintendent and say 'You know what, I don't want that fag teaching my child,' and that would be it. I'd be gone.

\section{Goal Three: Identify Factors That Promote Identity Consolidation}

The third goal of this investigation was identification of processes and experiences that promote identity consolidation among individuals with multiple minority identities. As noted earlier, half of the participants $(N=8)$ demonstrated having integrated their ethnic and sexual identities to a greater extent than their peers and thus it was important to examine differences between the two groups. First, demographic distinctions were readily apparent (refer to Table 2 ). There was a visible, although not statistically significant, age difference between the two groups. The mean age for the integrated group was 36 years compared to only 29 years for the less integrated group. All eight 
integrated participants completed higher education, whereas five of the eight participants in the less integrated group had completed high school. Relatedly, in the less integrated group there was more variance in annual income with an overall lower mode annual income. In addition, on the self-report measures the less integrated group demonstrated more variation across measures and almost all had an ethnic identity score that was below the sample mean.

Analyses of the in-depth interviews further revealed distinctive factors and processes that promoted identity consolidation. Table 3 provides a summary of participant statements revealing factors, processes, and outcomes of identity consolidation that were discovered in the analysis of the qualitative data.

Social "Support"

First, across all contexts it became apparent that real and perceived acceptance and support from others (especially loved ones) greatly influenced the degree to which people were able to more fully integrate their ethnic and sexual identities into a coherent whole. All of the participants that seemingly integrated these identities to a greater degree (i.e., "Interwoven") had disclosed their sexual identities to their immediate family, and the majority to their extended family as well. Although almost all participants verbalized a fear of rejection from their family upon disclosure of their sexual identity, the "interwoven" participants described positive reactions that included "support" and "acceptance." In addition, they verbalized an underlying trust that family relationships would be maintained even after disclosure of their sexual identity.

In contrast, although the majority of "struggling" participants had disclosed their sexual identity to some immediate family members (i.e., parents or siblings), they had not disclosed to all immediate family members nor extended family. These participants described experiencing negative reactions (i.e., "rejection") from family upon disclosure or discovery of their sexual identity and/or missing messages of "reassurance" that they would be accepted upon revealing their sexual identity. This skepticism of being supported socially appeared to directly influence their degree of integration. Despite their doubts, nearly all of these participants (except Fred and Seth) received some 
Table 3. Summary of Participant Statements Revealing Factors, Processes, and Outcomes of Identity Consolidation

"Struggling"

Social Support

Family
Accepting":
"I was very fortunate of having parents that
were very accepting and especially my mother.
So I very early, about fifteen years of age, it was
very clear that I was gay... my mother realized
what was going on... my mother was very clear
and told me 'that's the way that some people
are and that's okay.' So I did have that support"
(Leonardo)
"My family is very accepting." (Phillip)
Trust:
"I always knew that my parents would not
disown me; that didn't make any sense to me
knowing who they are." (Lucas)

"Rejection":

"They don't accept it [sexual identity] and they just don't believe it."(Frank)

"My mom, she knows from somebody else... that person told my mom horrible things... so my mom thought I was a very bad person... I had rejection from my mother because she was homophobic" (Joseph)

Missing "Reassurance":

"For the longest time I didn't tell my mom and dad that I was gay... . I didn't have the reassurance that it was going to be okay."(Juan)

"Accepting":
"I was very fortunate to go to a school that was
pretty accepting anyway and so [I] was involved
in GSA [Gay-Straight Alliance] before I identified
as gay or came out as gay" (Felicia)

Un-accepting:

"People I thought were my friends, I've lost communication with them or we totally went our separate ways after I came out to them and they didn't take it well ... . I have not come out to a lot of my teammates because just hearing or interacting with them ...." (Juan)

Occupational $\quad$ Asset:
"I think occupationally ... I have been expected
to be more sensitive to cultural differences
because of the fact that they know that I'm gay
and they know that I'm part of an ethnic group
... It has given me some credibility with some
individuals which I have worked and it has given
me some credibility with my colleagues as well"
(Leonardo)
Improved Relations with Others:
"Now I'm really happy with my family.... I think
everything changed after [disclosure]. Now I
have a better relationship with my sisters, with
my relatives, everything changed for the good."
(Horacio)
"Once they knew I was happy and there's nothing
I can do about being gay I think they felt better
about who I was and we felt better as a family
... I wanted to be close to my family and I think
this is the closest I've been after I came out."
(Rosa)

Liability:

"I hear them putting down other gay people and I just don't want to go there." (Linda)
Ongoing Difficulty and Distance in Relations with Others:

"It always gnaws at you when you just can't tell your family. I think if I were to come out they would not like me as much ... . It's a lack of communication that can really tear you up." (Seth)

"My extended family, not so much... they're just like these respectable Catholics [and] you just don't bring that up ... . You know, I don't feel like they need to know anything super personal about my life." (Alicia) 
Table 3 (continued). Summary of ParticipantStatements Revealing Factors, Processes, and Outcomes of Identity Consolidation

Consolidation Processes

Sequential Identity Work

"Learn[ing]" and "Exploring":

"I think it was one [identity] at a time for a while to learn more about each and become more comfortable with each." (John)

"It was interesting to explore my African-American side ... The high school that I went to I was really involved in tons of multicultural clubs, was in NAACP youth council... Then when I was exploring my sexuality and had a lot of gay friends and that sort of thing it wasn't really a balance-I think that to a degree I replaced my participation in my ethnic community with my participation in the gay community." (Felicia)
Negligible Exploration:

"I never paid too much attention about being Mexican or about being gay." (Joseph)

"I really, I could care less really [about ethnic and sexual identities], but it just bothers me what people think .... If they don't bring it to my attention to talk about, then I could care less." (Frank)
Integration Across Identity Domains

\section{Religious/Spiritual:}

"I'm studying it [religion] precisely because I'm gay. Being Black I think impacted my spiritual life in the sense that I grew up in the church .... I think it's being gay that's helped me to sort of wander out in the desert and realize there are flowers out there and to create spirituality in different ways than those that are given to me." (Lucas)

Ethnic and Gay Community Involvement:

"I was involved with the [ethnic] youth group. I would go to Mexican dances and stuff." (Humberto)

"I'm involved with the gay community .... We have a potluck once a month and... I go to the discussion group." (Leonardo)

\section{Laws/Policies:}

"It [being biracial and lesbian] influences my political party affiliation, the way I vote, the issues I pay attention to ... ." (Felicia)

"I'm always actually concerned about Affirmative Action and Equal Opportunity because I want to make sure, to the extent that I can, that everyone has a fair and just shake." (Lucas)
Religious/Spiritual:

"I still am a Christian. I kind of have some mixed views about things and sometimes I do feel like, you know, I'm letting my whole education and upbringing down but at the same point I feel like, you know, we are all children of God and we're all loved regardless. And so that's a mixed view when it comes to religion because, you know, it's hard." (Tammy)

Ethnic and Gay Community Involvement:

"I really don't get into my ethnic community. I tend to stay away from them, to be honest. I have no involvement unless I'm forced to with my parents." (Frank)

"I'm not involved in that type of ... fighting bad views of homosexuality. I'm not into any committees or anything that would stand up for homosexual rights." (Juan)

Laws/Policies:

"I'm not very political." (Joseph)

"I know there's a lot of controversy going on now about same-sex marriages. I don't know; I can see both sides of it and I really don't have an opinion, just whatever happens." (Tammy) 
Table 3 (continued). Summary of Participant Statements Revealing Factors, Processes, and Outcomes of Identity Consolidation

Consolidation Processes (continued)

Outcomes

\section{"Integrated":}

"I think earlier on I felt being an African-American was more important because, this was many years ago, even though I was actually actively engaging in sex with men I didn't believe that I would be gay in the end .... But then it seemed to me that being gay became more highlighted in a way. I used to read lots of things on African-American history, studies about AfricanAmericans, and then I would integrate that with lots of stuff on gay history and being gay. I've got through that phase of life and I actually liked that phase where everything in my life was gay; it was just everything. And so I existed in that space for quite sometime; it just feels like I'm in a space, at least in terms of a gay identity, where its just more integrated. I mean, gay isn't my entire life, [but it's] a very important part of my life that I treasure." (Lucas)

"Role Model":

"I see myself as more of a role model because I think that there are very few out there. As a gay male alone and being a minority, ethnic minority biracial, there aren't very many of us who selfidentify. So I portray myself every day as a positive role model to other young men. I have had the passion and the urge to be a leader and to be a role model in the community, a positive role and portrayal of a positive man." (John)
"Lob parts of yourself off":

"I think I've learned to keep it [sexual identity] under wraps when it's necessary .... You don't talk about things that are going to separate yourself from the group. You just lob parts of yourself off to appear in a way that's going to be similar to whatever situation you're in with people." (Seth)

"I don't make it a practice to sort of just go out and brag about it [sexual identity], but if you ask me I'll tell you, but most people are too afraid to ask so it really doesn't come out. No one really asked me so I really haven't had to lie or make anything up because no one has really asked."(Tammy) 
family support, which had also clearly influenced their level of integration. For example, Ramón stated, "All my sisters know [about sexual orientation] and they were like 'man, you work so hard you deserve to be happy in life.' ... They love me no matter what and they want me to be happy." Linda noted, "The two people most important to me in my life ... they said they loved me no matter what ...." Although all participants had disclosed their sexual identity to some of their friends, there were distinct differences between the two groups. Some "interwoven" participants verbalized receiving support and "acceptance" during childhood and adolescence from other non-heterosexual friends or social groups, while others received affirming responses from heterosexual friends upon disclosure of their sexual identity. For example, Leonardo stated, "I had the support from an early age identifying with other gay youngsters." Rosa commented,

After I came out to some of my friends and they're like 'oh we love you' and 'you're the best,' having the good, positive acceptance from my friends made me feel like 'you know, I don't care what everybody else thinks.' ... I appreciate my straight friends because I feel supported. It [disclosure] made us closer in a sense because I'm really who I am.

Although all "struggling" participants were out to at least some friends, their disclosure appeared to occur with caution and arose from different circumstances. Some participants disclosed to friends while working in a gay establishment or because of a romantic relationship. For example, Alicia stated, "If you meet somebody and you're just like, 'oh, this is my girlfriend' [to your friends]." Unfortunately, some also described losing friends after coming out and not disclosing to some friends for fear of losing the friendship.

Finally, a very obvious discrepancy between these two groups was seen in the occupational context. Almost all of the "interwoven" participants perceived their ethnic and sexual identities as an asset in the workplace and all had disclosed their sexual orientation to co-workers. Interestingly, six were currently employed in either an educational or cosmetology setting and viewed these domains, and the people in them, as safe and accepting. "Struggling" participants worked in a variety of areas ranging from human resources to manufacturing plants, and in contrast to their "interwoven" peers, the majority $(N=5)$ had not mixed these two identities in their occupational settings. It appears that they viewed disclosure of their 
sexual identity as a liability and were fearful to do so, as illustrated by Linda's comment: "I hear them putting down other gay people and I just don't want to go there."

Resulting from these clearly different experiences in social support and acceptance, the two groups of participants demonstrated distinct outcomes. The majority of "interwoven" participants described improved relationships with others (especially family) from increased levels of interaction and communication. However, those "struggling" participants appeared to have ongoing difficulty and distance from others. They voiced barriers to connecting and communicating, especially with family, and grappled with integrating these two identities.

\section{Sequential Identity Work}

A distinct process in identity consolidation was termed by these authors as sequential identity work. This phenomenon demonstrated by the "interwoven" participants was depicted as occurring through time (i.e., over many years), where one identity took precedence over another, until through education and exploration, participants arrived at a place where they committed to and equally valued both identities. Ethnicity tended to be the primary identifier first, and as exploration of their non-heterosexual identity occurred that then became primary until they held their ethnic and sexual identities as equally important and interdependent.

"Learn[ing]" and "exploring". Education and exploration appear critical to sequential identity work and by extension the process of identity consolidation. "Interwoven" participants described actively searching for information about their ethnicity and sexuality through extensive reading, research, study, travel, and participation in varied and diverse cultural activities and events. This was exemplified by Lucas's statement: "As it relates to those sort of subcultures [being African-American and gay], I am aware of the histories of both by participation and by study as well."

In contrast to their integrated peers, the "struggling" participants described negligible education or exploration experiences in the process of consolidating these identities. This lack of integration was evident in their verbalization of a lack of connection with either identity or unbalanced salience in these identities. For example, Juan 
commented, "Being Mexican and Hispanic will always be predominant..." and Seth said, "I don't think a lot of my culture .... I'd definitely say my sexual orientation is much more important ...."

Integration across identity domains. These education and exploration pursuits extended across various identity domains in the quest for consolidation. It was clearly evident in the religious context, where all of the "interwoven" participants described engaging in an assortment of behaviors (e.g., questioning, studying, investigating) and intentional decision making as they integrated a spiritual identity. For example, Phillip noted, "I've been to different kinds of churches ...." However, the "struggling" participants appeared to demonstrate foreclosure in this identity domain. For example, Ramón stated, "I still go to church like everybody else" and Juan commented, "I still go to church every Sunday because I'm so used to [it] I don't know anything different ...."

This integration (or lack of integration) extended to domains beyond religion. The "interwoven" participants appeared significantly more involved in their communities (ethnic and gay), more aware of laws or policies affecting multiple minority groups, and more politically active than their "struggling" peers. Most participants described taking part in their ethnic communities, through avenues such as social, religious, cultural activities/events, monetary donations, and/ or organization membership. All identified being actively involved in the gay community through opportunities such as monetary donations, benefit shows, volunteering, educational/support discussion groups, and organizational membership. All of them identified influential laws and policies (e.g., domestic partnership policies, affirmative action, marriage equality) and most engaged in some form of activism through involvement in one-on-one discussions, pride parades, educational presentations, awareness campaigns (e.g., National Coming Out Day) and organizations (e.g., Gay-Straight Alliance [GSA]).

In contrast, the "struggling" participants verbalized a lack of involvement in both communities. Nearly all indicated minimal involvement within their ethnic communities. Similarly, almost all reported minimal involvement in the gay community except for socializing with other non-heterosexual friends. Although a few referred to policies or laws (e.g., marriage equality) that may impact them or others, these references were vague and indicated a clear lack of conviction. All of these participants verbalized a general lack of political participation and denied any form of political activism. 


\section{Consolidation Outcomes}

The two groups of participants demonstrated distinct outcomes resulting from their active or passive integration of these two identities. The "interwoven" participants described a conscious process in which, after acquiring and accepting their minority sexual identity, they worked at consolidating both identities into an overall "self." They described their identity as having "evolved" and becoming "integrated." For example, Leonardo stated, "I was telling you earlier it [identity] has evolved ...."

In contrast, "struggling" participants appeared less intentional in their exploration and integration of their ethnic and sexual identities. Furthermore, they appeared to manage these dual minority identities through compartmentalization, often by actively monitoring themselves based on any given situation. It was described as "lob[bing] parts of yourself off" and summarized by Juan's comment, "If my family's involved then I'm not gay but I'm Mexican. I just can't function as a gay man around my family."

"Role model". Finally, all the integrated participants discussed various transactions with others where they intentionally engaged in education to help increase understanding and awareness. More specifically, several aspired to be role models for others because they recognized the absence of such during their own critical developmental periods, as illustrated by Humberto's comment:

You know, before when I didn't know other gay people or positive role models, I had a hard time .... I think the people who come out, this generation coming up, hopefully have it a lot easier than what I had, just because I had no role models. I feel like I'm a pioneer in some ways because I have to try to be a role model ....

\section{Discussion}

The primary goal of this research was to examine identity consolidation in ethnic and sexual minority individuals. In summarizing the findings, it appears that for lesbian and gay people of color integrating these two identities into a coherent whole is a process that occurs over time, requires intentional effort, and is significantly influenced by social context and the reactions of significant others within major 
life domains. All participants experienced oppression, either directly or indirectly, based on their ethnic or sexual (and often both) minority status and these encounters occurred in all social contexts (e.g., family, ethnic community, religious institution). Thus, the results of this investigation support the general conclusion that ethnic and sexual minority individuals experience multiple forms of oppression from various sources (Diaz, Bein, \& Ayala, 2006; Jamil et al., 2009; Meyer, 2010). However, the bottom line is that some demonstrated a greater degree of identity consolidation than others.

The participants who displayed a significant level of integration in their ethnic and sexual identities appeared to be older, more educated, showed consistently high scores (e.g., identity synthesis) across selfreport measures, had disclosed their sexual orientation to a greater variety of people (e.g., family, friends, coworkers), and verbalized a process of education and exploration in consolidating these two identities that appears to have motivated involvement in the ethnic and gay communities, awareness of laws or policies impacting minority group membership, and engagement in politics and/or activism. This is consistent with the developmental models that guided this study and past research that has framed identity integration as an inner sense of security regarding cultural identity and appreciation for one's own and the dominant culture (Phinney, 1989; Sue \& Sue, 1999), as well as acceptance and positive attitudes regarding sexual minority identity (Rosario et al., 2004). Furthermore, those with an integrated identity are reportedly comfortable disclosing their sexual identity to others (Cass, 1979; Rosario et al., 2004), typically involved in gay/lesbian activities (Rosario et al., 2004), and able to incorporate various identities into a coherent whole (Cass, 1979; Schwartz et al., 2010) consistently and across time (Schwartz et al., 2010), with motivation to eliminate oppression (Sue \& Sue, 1999). The “interwoven" participants in this investigation demonstrated, at least to some extent, each of these characteristics.

Furthermore, at least initially, the process of identity consolidation appeared to occur sequentially. This was typically described as an exploration and salience of ethnic identity, followed by immersion in sexual identity exploration that eventually led to equivalence of both identities within the self. This finding is similar to other studies that showed continual renegotiation where one minority identity is extremely salient, then replaced by the other, followed by 
experimentation and achievement of a sense of balance later in life (Operario, Han, \& Choi, 2008; Schnoor, 2006). Additional evidence for the concept of sequential identity work and the interdependence of these intersecting identities was highlighted in a recent qualitative study by Bowleg (2013). However, Jamil and colleagues (2009) found these two identities developed concurrently and participants engaged in only casual or covert exploration. Clearly, additional research in this area is needed.

Those participants who appeared to be having more difficulty in consolidating these two identities were typically younger, less educated, showed inconsistent or consistently low scores across self-report measures, were more selective in disclosing sexual orientation to others, participated minimally in ethnic and gay communities, verbalized negligible awareness of or involvement with laws/polices/activism, and appeared to manage these dual minority identities by compartmentalization. This strategy of compartmentalization supports other research indicating concealment of specific identities based on the context as illustrated with Latino gay men who did not view themselves as gay within the family context but identified as gay in a gay bar (Zea, Reisen, \& Diaz, 2003), Asian/Pacific Islander gay men who concealed their sexual orientation from family and ethnic community (Operario et al., 2008), or individuals who hid their sexual identity in order to maintain and enjoy participation in their Jewish religious community (Schnoor, 2006). The results of our study highlight that most of the struggling participants utilized compartmentalization across multiple life domains including family, friends, ethnic community, and occupation. Furthermore, this study's findings provide support for a structure of identity integration (e.g., low, high) in adults, where participants at different levels of integration significantly differ on markers of identity integration (e.g., less internalized homonegativity, more involvement in LGB activities, and positive attitudes toward non-heterosexuality) (Bregman et al., 2013; Rosario et al., 2008)

One of the most evident findings of the current investigation was the significance of social contexts to the process of identity development and integration. Acceptance from others was significant for self-acceptance and, by extension, identity consolidation. These findings clearly demonstrate support for the theoretical propositions of the bioecological model (Bronfenbrenner, 1979). In micro-system interactions, "interwoven" participants demonstrated, despite fear of 
rejection, an underlying trust that upon disclosing their sexual orientation they would not be abandoned by family, friends, etc. More importantly, they expressed receiving supportive reactions from significant others after disclosure, particularly within the family context. This supports quantitative research that found participants with a more positive non-heterosexual identity received significantly greater levels of social support (Vu et al., 2011). Relatedly, participants with an integrated identity perceived significantly more family support and significantly less parental rejection, sexual identity distress, and negative relationships with family and friends (Bregman et al., 2013; Rosario et al., 2008).

In contrast, those participants who were still struggling with integration described receiving more overt (and covert) messages of intolerance and negative reactions (e.g., denial, loss of relationship) from others upon disclosure of sexual orientation. These negative reactions appeared to reinforce participants' compartmentalization in order to manage their dual minority identities, often resulting in self-doubt, decreased relational intimacy, and diminished occupational capacity. Similarly, a qualitative study found African-American men who have sex with men described a sense of marginalization from the African-American community and of those that remained connected to their ethnic community, none self-identified as gay (Goode-Cross \& Good, 2009).

The influence of developmental interactions in other ecosystems was evident in our findings. As already noted, "interwoven" participants were distinctly more involved with their ethnic and gay communities and politically knowledgeable and active. This is similar to quantitative findings in which individuals with an achieved ethnic identity narrated more connection to their culture than those with lower levels of ethnic identity (Syed \& Azmitia, 2008) and individuals with more connection to the LGBTQ community demonstrated better psychological and social well-being (Kertzner et al., 2009). In addition, individuals that were more open about their minority sexual identity, regardless of race, engaged in more political activism (Swank \& Fahs, 2013).

Together, these findings raise questions about the nature of social support and related effects on consolidation. Some scholars have suggested that family acceptance and social support may be significant mediators of mental health outcomes (Chen \& Tryon, 2012; Kertzner et al., 2009). In addition, recent research examining type of social 
support found that participants reporting more sexuality-specific support were more likely to be categorized with an affirmed identity (Bregman et al., 2013). However, this sexuality-specific support was measured as coming from the family-which raises additional questions. Specifically, can strong social support in other contexts (e.g. schools, workplaces, houses of worship, etc.) overcome the debilitating impacts of family rejection so that consolidation ensues? Issues of quality and type of social support, in various contexts, and the relative impact of such on consolidation, are areas ripe for future research.

\section{Limitations and Future Research}

A significant strength of this study is that the participants were men and women of various ages and ethnic minorities from a Midwestern state, as studies with lesbian and gay people of color have been oversaturated with males, young to middle-aged persons, single ethnic minority groups, and coastal urban dwellers (DeBlaere et al., 2010; Huang et al., 2010; Phillips, 2010). Despite these strengths, the relatively small sample may have constrained opportunities for full identification of the identity consolidation process. If the sample had been drawn from rural areas, and/or other parts of the United States where there are more inclusive laws, policies, and views regarding minorities, different themes may have emerged regarding identity consolidation for ethnic and sexual minorities. Thus, future research would be well advised to develop and implement more effective sampling strategies to gather a more diverse sample in an effort to provide a more holistic understanding of the processes of identity consolidation.

The current body of literature lacks an assessment instrument to measure consolidation for ethnic and sexual minorities. Thus, consolidation was determined using verbal reports and self-report measures that assessed ethnic and sexual identity integration independently, which at times appeared contradictory, especially for those participants who were struggling with integration. The development of a valid and reliable instrument to gauge consolidation would significantly aid understanding and provide new avenues for investigation.

Finally, it is important to note that the processes involved in identity consolidation are not mutually exclusive. For instance, messages of acceptance and tolerance for difference, especially in the family 
realm, likely encourage education and exploration efforts. The more one learns about one minority identity, the greater the likelihood he or she will explore other aspects of self and engage more critically in sequential identity work. Simply stated, we argue that none of the processes deemed beneficial to identity consolidation, as described in this study, occur in a vacuum, but rather work in concert as interdependent agents of change. Continued research delineating these processes, and efforts to promote each, are also recommended.

\section{Implications}

Chen and Tryon (2012) found that greater levels of sexual minority stress (e.g., internalized homophobia, perceived stigma) are linked to lower levels of self-esteem and more psychological distress. The fact that half of the participants in this study described continuing to labor with integrating these identities, well into adulthood, suggests that individuals with multiple minority statuses may greatly benefit from formalized assistance to help them through the processes involved in identity consolidation, especially because it appears that at stake are serious and possibly long-term consequences on psychological and emotional well-being.

Access to positive role models with similar minority identities may be crucial to facilitating integration. In this study, the integrated participants clearly articulated effects from the absence of role models during critical developmental periods. This is particularly interesting given results of recent studies highlighting that sexuality-specific social support is directly associated with an affirmed identity and may moderate emotional distress, yet is perceived to be more available from sexual minority friends than family or heterosexual friends (see Bregman et al., 2013; Doty, Willoughby, Lindahl, \& Malik, 2010). Perceived type of support, as well as support providers, is ripe for further research, especially in an effort to identify effective interventions and outreach that may assist others struggling to integrate multiple aspects of self. Interestingly, a very recent qualitative study concluded that identity integration appeared to be directly facilitated through relations with a gay mentor (Sheran \& Arnold, 2012). Finally, future research should focus on developing and implementing culturally based and targeted family interventions (e.g., educational programs), especially during childhood and adolescence, to assist families 
with moving beyond awareness and acceptance of their non-heterosexual family member to gaining the skills necessary to provide sexuality-specific support.

\section{References}

Adams, C. L., Jr., \& Kimmel, D. C. (1997). Exploring the lives of older African American gay men. In B. Greene (Ed.), Ethnic and cultural diversity among lesbians and gay men: Psychological perspectives on lesbian and gay issues (pp. 132-151). Thousand Oaks, CA: SAGE Publications.

Adams, H. L., \& Phillips, L. (2009). Ethnic related variations from the Cass model of homosexual identity formation: The experiences of two-spirit, lesbian and gay Native Americans. Journal of Homosexuality, 56(7), 959-976.

Aronson, J. (1994). A pragmatic view of thematic analysis. The Qualitative Report, 2(1). http://www.nova.edu/ssss/QR/BackIssues/QR2-1/aronson.html

Bowleg, L. (2013). “Once you've blended the cake, you can't take the parts back to the main ingredients": Black gay and bisexual men's description and experiences of intersectionality. Sex Roles, 68, 754-767.

Boyatzis, R. E. (1998). Transforming qualitative information: Thematic analysis and code development. Thousand Oaks, CA: SAGE Publications.

Bregman, H. R., Malik, N. M., Page, M. J. L., Makynen, E., \& Lindahl, K. M. (2013). Identity profiles in lesbian, gay, and bisexual youth: The role of family influences. Journal of Youth Adolescence, 42, 417-430. doi: 10. 1007/ s10964-012-9798-z

Brady, S., \& Busse, W. (1994). The gay identity questionnaire: A brief measure of homosexual identity formation. Journal of Homosexuality, 26, 1-22.

Bronfenbrenner, U. (1979). The ecology of human development: Experiments by nature and design. Cambridge, MA: Harvard University Press.

Bronfenbrenner, U., \& Morris, S. (2006). The bioecological model of human development. In W. Damon \& R. M. Lerner (Eds.), Handbook of child psychology (6th ed., vol. 1, pp. 793-823). Hoboken, NJ: John Wiley \& Sons.

Cass, V. C. (1979). Homosexual identity formation: A theoretical model. Journal of Homosexuality, 4, 219-235.

Cass, V. C. (1984). Homosexual identity formation: Testing a theoretical model. The Journal of Sex Research, 20, 143-167.

Chan, C. S. (1993). Issues of identity development among Asian American lesbian and gay men. In L. Garnets \& D. Kimmel (Eds.), Psychological perspectives on lesbian and gay male experiences (pp. 376-387). New York, NY: Columbia University Press.

Chen, Y. C., \& Tryon, G. S. (2012). Dual minority stress and Asian American gay men's psychological distress. Journal of Community Psychology, 4o(5), 539-554. 
Chun, K. Y. S., \& Singh, A. A. (2010). The bisexual youth of color intersection identities development model: A contextual approach to understanding multiple marginalization experiences. Journal of Bisexuality, 10, 429-451. doi: 10.1080/15299716.2010.521059

Cochran, S. D., \& Mays, V. M. (2009). Burden of psychiatric morbidity among lesbian, gay, and bisexual individuals in the California Quality of Life Survey. Journal of Abnormal Psychology, 118(3), 647-658.

Colon, E. (2001). An ethnographic study of six Latino gay and bisexual men. Journal of Gay \& Lesbian Social Services, 12, 77-92.

Constantine, M. G., Richardson, T. Q., Benjamin, E. M., \& Wilson, J. W. (1998). An overview of Black racial identity theories: Limitations and considerations for future theoretical conceptualizations. Applied and Preventative Psychology, 7 , 95-99.

Coté, J. E., \& Levine, C. G. (2002). Identity formation, agency and culture: A social psychological synthesis. Mahwah, NJ: Lawrence Erlbaum.

Crawford, I., Allison, K. W., Zamboni, B. D., \& Soto, T. (2002). The influence of dual-identity development on the psychosocial functioning of African American gay and bisexual men. Journal of Sex Research, 39, 179-190.

Creswell, J. W. (2007). Qualitative inquiry and research design choosing among five approaches. Thousand Oaks, CA: SAGE.

Creswell, J. W., \& Plano Clark, V. L. (2011). Designing and conducting mixed methods research. Thousand Oaks, CA: SAGE.

Cross W. E., Jr. (1971). The negro-to-black conversion experience. Black World, 2O(9), 13-27.

Cross, W. E., Jr. (1995). The psychology of nigrescence: Revising the Cross model. In J. Ponterotto, J. Casas, L. Suzuki, \& C. Alexander (Eds.), Handbook of multicultural counseling (pp. 93-122). Thousand Oaks, CA: SAGE.

DeBlaere, C., Brewster, M. E., Sarkees, A., \& Moradi, B. (2010). Conducting research with LGB people of color: Methodological challenges and strategies. The Counseling Psychologist, 38, 331-362. doi: 10.1177/0011000oo 9335257

Degges-White, S. E., \& Myers, J. E. (2005). The adolescent lesbian identity formation model: Implications for counseling. The Journal of Humanistic Counseling, Education and Development, 44(2), 185-197.

Degges-White, S., Rice, B., \& Myers, J. E. (200o). Revisiting Cass' theory of sexual identity formation: A study of lesbian development. Journal of Mental Health Counseling, 22, 318-336.

Denzin, N. K., \& Lincoln, Y. S. (2011). The discipline and practice of qualitative research. In N. K. Denzin \& Y. S. Lincoln (Eds.), The SAGE handbook of qualitative research (pp. 1-25). Thousand Oaks, CA: SAGE.

Diamond, L. M. (1998). Development of sexual orientation among adolescent and young adult women. Developmental Psychology, 34(5), 1085-1095.

Diamond, L. M. (2000). Sexual identity, attractions, and behavior among young sexual-minority women over a 2-year period. Developmental Psychology, 36(2), 241-250. 
Diamond, L. M. (2003). Was it a phase? Young women's relinquishment of lesbian/bisexual identities over a 5-year period. Journal of Personality and Social Psychology, 84(2), 352-364.

Diamond, L. M. (2005). A new view of lesbian subtypes: Stable versus fluid identity trajectories over an 8-year period. Psychology of Women Quarterly, 29(2), 119-128.

Diaz, R. M., Bein, E., \& Ayala, G. (2006). Homophobia, poverty, and racism: Triple oppression and mental health outcomes in Latino gay men. In A. M. Omoto \& H. S. Kurtzman (Eds.), Sexual orientation and mental health: Examining identity and development in lesbian, gay, and bisexual people (1st ed., pp. 207-224). Washington, DC: American Psychological Association.

Doty, N. D., Willoughby, B. L. B., Lindahl, K. M., \& Malik, N. M. (2010). Sexuality related social support among lesbian, gay, and bisexual youth. Journal of Youth and Adolescence, 39(10), 1134-1147. doi: 10.1007/s10964-010-9566-x

Dubé, E. M. (2000). The role of sexual behavior in the identification process of gay and bisexual males. Journal of Sex Research, 37(2), 123-132.

Dubé, E. M., \& Savin-Williams, R. C. (1999). Sexual identity development among ethnic sexual-minority male youths. Developmental Psychology, 35(6), 1389-1398.

Dunkel, C. S. (2005). The relation between self-continuity and measures of identity. Identity: An International Journal of Theory and Research, 5(1), 21-34.

Ellis, A. L., \& Mitchell, R. W. (2000). Sexual orientation. In L. Szuchman, F. Muscarella, A. Ellis, \& R. Mitchell (Eds.), Psychological perspectives on human sexuality (pp. 196-231). New York, NY: John Wiley and Sons, Inc.

Erikson, E. H. (1968). Identity, youth, and crises. New York, NY: Norton.

Espin, O. M. (1993). Issues of identity in the psychology of Latina lesbians. In L. Garnets \& D. Kimmel (Eds.), Psychological perspective on lesbian and gay male experiences (pp. 348-363). New York, NY: Columbia University Press.

Fassinger, R. E., \& Miller, B. A. (1996). Validation of an inclusive model of sexual minority identity formation on a sample of gay men. Journal of Homosexuality, 32, 53-78.

Feldman, S. E., \& Wright, J. (2013). Dual impact: Outness and LGB identity formation on mental health. Journal of Gay \& Lesbian Social Services, 25(4), 443- 464 .

Foster, E. M., \& Kalil, A. (2005). Developmental psychology and public policy: Progress and prospects. Developmental Psychology, 41, 827-832.

Frable, D. E. S. (1997). Gender, racial, ethnic, sexual, and class identities. Annual Review of Psychology, 48, 139-162.

Galliher, R. V., Jones, M. D., \& Dahl, A. (2011). Concurrent and longitudinal effects of ethnic identity and experiences of discrimination on psychosocial adjustment of Navajo adolescents. Developmental Psychology, 47(2), 509-526. doi: 10.1037/aoo21061

Gallor, S. M., \& Fassinger, R. E. (2010). Social support, ethnic identity, and sexual identity of lesbians and gay men. Journal of Gay \& Lesbian Social Services, 22, 287-315. 
Goode-Cross, D. T., \& Good, G. E. (2009). Managing multiple-minority identities: African American men who have sex with men at predominately White universities. Journal of Diversity in Higher Education, 2(2), 103-112.

Graber, J. A., \& Archibald, A. B. (2001). Psychosocial change at puberty and beyond: Understanding adolescent sexuality and sexual orientation. In A.

D’Augelli \& C. Patterson (Eds.), Lesbian, gay, and bisexual identities and youth: Psychological perspectives (pp. 3-26). New York, NY: Oxford University Press.

Greene, B. (1997). Ethnic minority lesbians and gay men: Mental health and treatment issues. In B. Greene (Ed.), Ethnic and cultural diversity among lesbians and gay men: Psychological perspectives on lesbian and gay issues (pp. 216239). Thousand Oaks, CA: SAGE.

Greene, D. C., \& Britton, P. J. (2013). Stage of sexual minority identity formation: The impact of shame, internalized homophobia, ambivalence over emotional expression, and personal mastery. Journal of Gay \& Lesbian Mental Health, 16(3), 188-214.

Greene, J. C., \& Hall, J. N. (2010). Dialectics and pragmatism: Being of consequence. In A. Tashakkori \& C. Teddlie (Eds.), SAGE handbook of mixed methods in social and behavioral research (2nd ed., pp. 119-143). Thousand Oaks, CA: SAGE.

Grotevant, H. D. (1987). Toward a process model of identity formation. Journal of Adolescent Research, 2, 203-222. doi: 10.1177/074355488723003

Harper, G. W., Jernewall, N., \& Zea, M. C. (2004). Giving voice to emerging science and theory for lesbian, gay, and bisexual people of color. Cultural Diversity and Ethnic Minority Psychology, 10(3), 187-199.

Herek, G. M., \& Garnets, L. D. (2007). Sexual orientation and mental health. Annual Review of Clinical Psychology, 3, 353-375. doi: 10.1146/annurev. clinpsy.3.022806.091510

Huang, Y. P., Brewster, M. E., Moradi, B., Goodman, M. B., Wiseman, M. C., \& Martin, A. (2010). Content analysis of literature about LGB people of color: 1998-2007. The Counseling Psychologist, 38, 363-396. doi: 10.1177/0011000009335255

Jamil, O. B., Harper, G. W., \& Fernandez, M. I. (2009). Sexual and ethnic identity development among gay-bisexual- questioning (GBQ) male ethnic minority adolescents. Cultural Diversity and Ethnic Minority Psychology, 15(3), 203-214.

Johnson, R. B., \& Onwuegbuzie, A. J. (2004). Mixed methods research: A research paradigm whose time has come. Educational Researcher, 33(7), 14-26. Kahn, M. J. (1991). Factors affecting the coming out process for lesbians. Journal of Homosexuality, 21, 47-70.

Kertzner, R. M., Meyer, I. H., Frost, D. M., \& Stirratt, M. J. (2009). Social and psychological well-being in lesbians, gay men, and bisexuals: The effects of race, gender, age, and sexual identity. American Journal of Orthopsychiatry, 79(4), 500-510.

Levine, H. (1997). A further exploration of the lesbian identity development process and its measurement. Journal of Homosexuality, 34, 67-78. 
Loiacano, D. K. (1993). Gay identity issues among Black Americans: Racism, homophobia, and the need for validation. In L. Garnets \& D. Kimmel (Eds.), Psychological perspectives on lesbian and gay male experiences. New York, NY: Columbia University Press.

Luyckx, K., Goossens, L., Soenens, B., \& Beyers, W. (2006). Unpacking commitment and exploration: Preliminary validation of an integrative model of late adolescent identity formation. Journal of Adolescence, 29, 361-378.

Luyckx, K., Schwartz, S. J., Goossens, L., \& Pollock, S. (2008). Employment, sense of coherence, and identity formation: Contextual and psychological processes on the pathway to sense of adulthood. Journal of Adolescent Research, 23, 566-591.

Martinez, R. O., \& Dukes, R. L. (1997). The effects of ethnic identity, ethnicity, and gender on adolescent well-being. Journal of Youth and Adolescence, 26(5), 503-516.

Merriam, S. B. (2009). Qualitative research: A guide to design and implementation. San Francisco, CA: John Wiley \& Sons.

Meyer, I. H. (2003). Prejudice, social stress, and mental health in lesbian, gay, and bisexual populations: Conceptual issues and research evidence. Psychological Bulletin, 129(5), 674-697.

Meyer, I. H. (2010). Identity, stress, and resilience in lesbians, gay men and bisexuals of color. The Counseling Psychologist, 38(3), 442-454. doi: 10.1177/0011000009351601

Miranda, R., Polanco-Roman, L., Tsypes, A., \& Valderrama, J. (2013). Perceived discrimination, ruminative subtypes, and risk for depressive symptoms in emerging adulthood. Cultural Diversity and Ethnic Minority Psychology, 19(4), 395-403.

Mohr, J. J., \& Kendra, M. S. (2011). Revision and extension of a multidimensional measure of sexual minority identity: The lesbian, gay, and bisexual identity scale. Journal of Counseling Psychology, 58(2), 234-245. doi: 10.1037/ aoo22858

Morgan, E. M. (2012). Contemporary issues in sexual orientation and identity development in emerging adulthood. Emerging Adulthood, 1(1), 52-66.

Mossakowski, K. N. (2003). Coping with perceived discrimination: Does ethnic identity protect mental health? Journal of Health and Social Behavior, 44(3), 318-331.

Narváez, R. F., Meyer, I. H., Kertzner, R. M., Ouellette, S. C., \& Gordon, A. R. (2009). A qualitative approach to the intersection of sexual, ethnic, and gender identities. Identity: An International Journal of Theory and Research, 9, 63-86. doi: 10.1080/15283480802579375

Ong, A. D., Fuller-Rowell, T. E., \& Phinney, J. S. (2010). Measurement of ethnic identity: Recurrent and emergent issues. Identity: An International Journal of Theory and Research, 10(1), 39-49.

Operario, D., Han, C. S., \& Choi, K. H. (2008). Dual identity among gay Asian Pacific Islander men. Culture, Health, and Sexuality, 10(5), 447-461. 
Parks, C. A., Hughes, T. L., \& Matthews, A. K. (2004). Race/ethnicity and sexual orientation: Intersecting identities. Cultural Diversity and Ethnic Minority Psychology, 10(3), 241-254.

Parent, M. C., DeBlaere, C., \& Moradi, B. (2013). Approaches to research on intersectionality: Perspectives on gender, LGBT, and racial/ethnic identities. Sex Roles, 68, 639-645.

Phillips, J. C. (2010). Eight articles, eight journals, eight years: Selected disappointments and celebrations from an outstanding major contribution. The Counseling Psychologist, 38, 363-396. doi: 10.1177/0011000009346324

Phinney, J. S. (1989). Stages of ethnic identity development in minority group adolescents. The Journal of Early Adolescence, 9, 271-280.

Phinney, J. S. (1992). The multigroup ethnic identity measure: A new scale for use with diverse groups. Journal of Adolescent Research, 7, 156-176.

Phinney, J. S. (1993). A three-stage model of ethnic identity development in adolescence. In M. Bernal \& G. Knight (Eds.), Ethnic identity: Formation and transmission among Hispanics and other minorities (pp. 61-79). Albany, NY: State University of New York Press.

Phinney, J. S. (2008). Bridging identities and disciplines: Advances and challenges in understanding multiple identities. In M. Azmitia, M. Syed, \& K. Radmacher (Eds.), The inter-sections of personal and social identities: New directions for child and adolescent development, 120, 97-109. doi: 10.1002/ed.218

Phinney, J. S., \& Alipuria, L. L. (1990). Ethnic identity in college students from four ethnic groups. Journal of Adolescence, 13, 171-183.

Phinney, J. S., Cantu, C. L., \& Kurtz, D. A. (1997). Ethnic and American identity as predictors of self-esteem among African American, Latino, and White adolescents. Journal of Youth and Adolescence, 26, 165-185.

Phinney, J. S., \& Chavira, V. (1992). Ethnic identity and self-esteem: An exploratory longitudinal study. Journal of Adolescence, 15, 271-281.

Phinney, J. S., \& Rosenthal, D. A. (1992). Ethnic identity in adolescence: Process, context, and outcome. In G. R. Adams, T. P. Gullotta, \& P. Thomas (Eds.), Adolescent identity formation: Advances in adolescent development (pp. 145-172). Newbury Park, CA: SAGE.

Pyant, C. T., \& Yanico, B. J. (1991). Relationship of racial identity and gender-role attitudes to Black women's psychological well-being. Journal of Counseling Psychology, 38, 315-322.

Roberts, R. E., Phinney, J. S., Masse, L. C., Chen, Y. R., Roberts, C. R., \& Romero, A. (1999). The structure of ethnic identity of young adolescents from diverse ethnocultural groups. The Journal of Early Adolescence, 19(3), 301-322.

Rosario, M., Schrimshaw, E. W., \& Hunter, J. (2004). Ethnic/racial differences in the coming-out process of lesbian, gay, and bisexual youths: A comparison of sexual identity development over time. Cultural Diversity and Ethnic Minority Psychology, 10(3), 215-228.

Rosario, M., Schrimshaw, E. W., \& Hunter, J. (2008). Predicting different patterns 
of sexual identity development over time among lesbian, gay, and bisexual youths: A cluster analytic approach. American Journal of Community Psychology, 42(3-4), 266-282.

Rosario, M., Schrimshaw, E. W., Hunter, J., \& Braun, L. (2006). Sexual identity development among lesbian, gay, and bisexual youths: Consistency and change over time. Journal of Sex Research, 43(1), 46-58.

Rotheram-Borus, M. J., \& Langabeer, K. A. (2001). Developmental trajectories of gay, lesbian, and bisexual youths. In A. R. D’Augelli \& C. J. Patterson (Eds.), Lesbian, gay, and bisexual identities over the lifespan: Psychological perspectives (pp. 97-128). New York, NY: Oxford University Press.

Russell, S. T., Ryan, C., Toomey, R. B., Diaz, R. M., \& Sanchez, J. (2011). Lesbian, gay, bisexual, and transgender adolescent school victimization: Implications for young adult health and adjustment. Journal of School Health, 81(5), 223-230.

Savin-Williams, R. C. (2005). The new gay teenager. Cambridge, MA: Harvard University Press.

Savin-Williams, R. C., \& Diamond, L. M. (2000). Sexual identity trajectories among sexual-minority youths: Gender comparisons. Archives of Sexual Behavior, 29(6), 607-627.

Savin-Williams, R. C., \& Rodriguez, R. G. (1993). A developmental, clinical perspective on lesbian, gay male, and bisexual youths. In T. P. Gullotta, G. R. Adams, \& R. Montemayor (Eds.), Adolescent sexuality: Vol. 5. Advances in adolescent development (pp. 77-101). Newbury Park, CA: SAGE.

Schnoor, R. F. (2006). Being gay and Jewish: Negotiating intersecting identities. Sociology of Religion, 67(1), 43-6o.

Schwartz, S. J., Forthun, L. F., Ravert, R. D., Zamboango, B. L., Umaña-Taylor, A. J., Filton, B. J., ... Hudson, M. (2010). Identity consolidation and health risk behaviors in college students. American Journal of Health Behavior, 34(2), 214-224.

Sheran, N., \& Arnold, E. A. (2012). Fairy godmothers and guardian angels: A qualitative study of the gay mentorship relationship. Journal of Gay \& Lesbian Social Services, 24, 201-220.

Smith, T. B., \& Silva, L. (2011). Ethnic identity and personal well-being of people of color: A meta-analysis. Journal of Counseling Psychology, 58(1), 42-60.

Sophie, J. (1986). A critical examination of stage theories of lesbian identity development. Journal of Homosexuality, 12, 39-51.

Sue, D. W., \& Sue, D. (1999). Counseling the culturally different: Theory and practice (3rd ed.). New York, NY: John Wiley \& Sons, Inc.

Swank, E., \& Fahs, B. (2013). An intersectional analysis of gender and race for sexual minorities who engage in gay and lesbian rights activism. Sex Roles, 68, 668-674.

Syed, M., \& Azmitia, M. (2008). A narrative approach to ethnic identity in emerging adulthood: Bringing life to the identity status model. Developmental Psychology, 44(4), 1012-1027. 
Teddlie, C., \& Yu, F. (2007). Mixed methods sampling: A typology with examples. In V. L. Plano Clark \& J. W. Creswell (Eds.), The mixed methods reader (pp. 199228). Thousand Oaks, CA: SAGE. (Reprinted from Journal of Mixed Methods Research, 1[1], pp. 77-100).

Tragakis, M. W., \& Smith, J. L. (2010). The relation between social identity integration and psychological adjustment: A focus on mainstream and marginalized cultural identities. Identity: An International Journal of Theory and Research, 10(3), 201-221.

Umaña-Taylor, A. J. (2004). Ethnic identity and self-esteem: Examining the role of social context. Journal of Adolescence, 27(2), 139-146.

Umaña-Taylor, A. J., \& Fine, M. A. (2004). Examining ethnic identity among Mexican-origin adolescents living in the United States. Hispanic Journal of Behavioral Sciences, 26, 36-59. doi: 10.1177/0739986303262143

Vandiver, B. J. (2001). Psychological nigrescence revisited: Introduction and overview. Journal of Multicultural Counseling and Development, 29, 165-174.

Vu, L., Choi, K. H., \& Do, T. (2011). Correlates of sexual, ethnic, and dual identity: A study of young Asian and Pacific Islander men who have sex with men. AIDS Education and Prevention, 23(5), 423-436.

Zea, M. C., Reisen, C. A., \& Diaz, R. M. (2003). Methodological issues in research with Latino gay and bisexual men. American Journal of Community Psychology, 31, 281-291. 